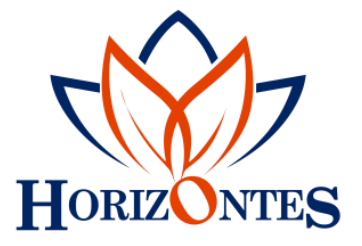

www.revistahorizontes.org

\title{
Didáctica virtual y desempeño académico en estudiantes de maestrías de educación de la PUCE - Ambato
}

\author{
Virtual Didactic and academic performance in students of education masters of la \\ PUCE - Ambato
}

Didática virtual e desempenho acadêmico em alunos do mestrado em educação da PUCE - Ambato

ARTÍCULO DE REVISIÓN

\author{
Luis Alvián Abad Tandazo \\ luis.a.abad.t@pucesa.edu.ec
}

\section{Helder Marcell Barrera Erreyes}

hbarrera@pucesa.edu.ec

ORCID: 0000 - 0001-8196-3797

\section{Pontificia Universidad Católica Del Ecuador - Sede Ambato, Ecuador}

Recibido 04 de febrero 2021 | Arbitrado y aceptado 16 de febrero 2021 | Publicado en marzo 2021

\section{RESUMEN}

El artículo sobre la "Didáctica Virtual y el Desempeño Académico de los estudiantes en las Maestrías de Educación de la PUCE-Ambato", describe cómo los docentes con título de tercer nivel siguen el reto de formación profesional de una maestría en un contexto de estudios de modalidad virtual considerando el momento de pandemia que altera significativamente factores bio-psicosociales, los objetivos son; fundamentar teórica y metodológicamente el desarrollo de la didáctica virtual en el desempeño académico de los estudiantes, diagnosticar en los maestrantes la verificación del desempeño académico y evaluar teóricamente la didáctica virtual en el desempeño académico de los estudiantes de las maestrías, la metodología que se aplicará tiene un alcance explicativo y descriptivo. La modalidad es cualitativa de tipo bibliográfica. Entre las conclusiones se evidencia que la didáctica virtual es significativa dependiendo de las metodologías aplicadas por el docente y en educación on-line el uso de herramientas tecnológicas didácticas que interactúen en clase, el desempeño académico tiene factores externos que afectan áreas afectivas, laborales y familiares, más aún en tipos de pandemia.

Palabras clave: Didáctica Virtual; desempeño académico; educación

\section{ABSTRACT}

The article on "Virtual Didactics and the Academic Performance of the students in the Masters of Education of the PUCE-Ambato", describes how teachers with a third level degree follow the challenge of professional training of a master's degree in a context of studies of virtual modality considering the moment of pandemic that significantly alters bio-psycho-social factors, the objectives are; theoretically and methodologically base the development of virtual didactics in the academic performance of students, diagnose in the teachers the verification of academic performance and theoretically evaluate virtual didactics in the academic performance of the students of the master's degrees, the methodology that will be applied has an explanatory and descriptive scope. The modality is qualitative, bibliographic type. Among the conclusions, it is evident that virtual didactics is significant depending on the methodologies applied by the teacher and in online education the use of didactic technological tools that interact in class, academic performance has external factors that affect affective, work and family areas, even more so in types of pandemic.

Key words: Virtual Didactics; academic performance; education 


\section{RESUMO}

0 artigo "Didática Virtual e Desempenho Acadêmico dos Alunos do Mestrado em Educação da PUCE-Ambato", descreve como professores de terceiro grau seguem o desafio da formação profissional de um mestrado em contexto da modalidade de estudos virtuais considerando o momento de pandemia que altera significativamente os fatores biopsicossociais, os objetivos são; Com base teórica e metodológica no desenvolvimento da didática virtual no desempenho acadêmico dos alunos, diagnosticar nos professores a verificação do desempenho acadêmico e avaliar teoricamente a didática virtual no desempenho acadêmico dos alunos dos mestrados, a metodologia a ser aplicada tem um escopo explicativo e descritivo. A modalidade é qualitativa, do tipo bibliográfico. Dentre as conclusões, fica evidente que a didática virtual é significativa dependendo das metodologias aplicadas pelo professor e na educação online o uso de ferramentas tecnológicas didáticas que interagem em sala de aula, o desempenho acadêmico possui fatores externos que afetam as áreas afetiva, de trabalho e familiar, inclusive. Mais ainda em tipos de pandemia.

Palavras-chave: Didática Virtual; desempenho acadêmico; educação

\section{INTRODUCCIÓN}

Debido a la emergencia sanitaria que está atravesando la humanidad por la propagación del (COVID-19) que obliga a las familias a permanecer aisladas especialmente en el campo educativo, en el Ecuador desde el 13 de marzo de 2020, el sistema educativo en el régimen Sierra y Amazonía suma más de dos millones de estudiantes de educación primaria, secundaria, bachillerato y superior, que no acuden a las aulas, dando paso a un reto de grandes dimensiones: la educación en línea. Este desafío implica, por un lado, el acceso a herramientas $\mathrm{y}$, por otro, la práctica de las habilidades de los profesores para impartir conocimientos vía online.
La didáctica virtual tiene una connotación muy significativa para la aplicación y el conocimiento del estudiante universitario. Según Pérez (2016) se debe organizar, conocer y planificar la clase, para que en el aula se haga buen uso de la didáctica adecuada en el desarrollo de la asignatura. Así conoceremos algunos aspectos a la hora de diseñar una propuesta de innovación educativa; diagnóstico de necesidades, finalidad de la innovación, recursos disponibles, áreas de actuación.

Estos aspectos son de mucha relevancia según Martínez y Heredia (2010) para realizar un diseño innovador en la aplicación de la educación virtual. Esto nos ayuda a propiciar la actividad cognitiva y el aprendizaje de los estudiantes on-line, para lo cual debe haber un cambio y mejoramiento de su comportamiento y compromiso, tanto en los planteamientos como en las propuestas pedagógicas, metodologías, estrategias y recursos a utilizarse. El sistema educativo mundial se transformó en tiempo récord a lo que nunca se imaginó el orbe, con ello llegaron beneficios y consecuencias. Por lo tanto, se describe algunos de los problemas visibles en las aulas virtuales. Como causa, está la falta de conocimiento de herramientas tecnológicas tanto de estudiantes y de algunos docentes de la maestría en educación de la PUCE - Ambato. Con la amplitud y apertura en educación a una nueva etapa virtual, obliga a auto educarse tanto a estudiantes como a profesores de manera que se facilite el aprendizaje, porque las tecnologías están para hacer más fácil el aprendizaje.

Las herramientas metodológicas ayudan a descubrir una mejor enseñanza y aprendizaje para lograr mayor eficacia en el desarrollo del conocimiento, destrezas y competencias. Se 
está evidenciando en los estudiantes de todos los niveles que ponen sus quejas en la falta de preparación e innovación de metodologías para impartir las clases virtuales. Para los estudiantes de maestría en educación de la PUCE - Ambato, no ha sido la excepción en preparación, innovación y conocimiento de las nuevas herramientas que están disponibles desde años atrás para un mejor desarrollo de las clases virtuales. Así mismo la velocidad que va alcanzando la tecnología, deja con un retraso abismático a los estudiantes de todos los niveles y de posgrado, que desconocen nuevos programas, equipos, plataformas, es decir se estacionaron causando un incipiente dominio de las tecnologías.

La desactualización de la tecnología, encierra al estudiante en un espacio desconocido sin salida, sin apertura, perdiendo la riqueza que conlleva el conocer y descubrir las nuevas herramientas, automáticamente trae como efecto en el estudiante retraso en la entrega de trabajo y discontinuidad en el aprendizaje. Cada persona tiene su propia historia que se va generando desde el primer hogar, en los primeros años de vida mientras se va alcanzando etapas, cada uno también va cumpliendo metas, así hasta convertirse en un profesional de su país. En ese lapso se suscitan diferentes vivencias, en la niñez en la educación primaria, en el colegio en la secundaria y a nivel superior. Al no mantenerse en continuidad académica se arrastra el desconocimiento de la tecnología que cada día se actualiza, así lo demuestran los estudiantes de la maestría en educación, que han descontinuado su proceso educativo, lo que trae como efecto la desmotivación y pérdida de habilidades en la comprensión de contenidos y un retraso en la asimilación de los mismos.
La renovación y actualización de conocimientos, así como la evaluación debería ser una política de estado para todas las sociedades del planeta, pero, conocemos las realidades y sus debilidades en ello; lo que impide que se cumpla con este anhelo que es todo estudiante el de renovar sus conocimientos de una forma permanente; si es que no se invierte recursos económicos propios no se puede continuaron con la actualización e innovación. Se está vivenciando en las clases virtuales de maestría en educación, que el tiempo para el desarrollo y comprensión de cada módulo es limitado y corto, el vacío que queda en el maestrante es amplio, difícil de cubrir en pocas horas de enseñanza, lo que genera como efecto un apresuramiento en el desarrollo de las tareas de cada estudiante $y$ en el docente, el cumplimiento de la planificación que nace en la universidad, lo que no permite una amplitud en el conocimiento y desarrollo de las destrezas y competencias que se necesita para perfeccionar cada módulo.

Para ello se plantea el problema científico: ¿Cuál es la incidencia de la didáctica virtual en el desempeño académico de los estudiantes en las maestrías de educación de la PUCEAmbato? y plantearnos los siguientes objetivos, analizar la incidencia de la didáctica virtual en el desempeño académico de los estudiantes en las maestrías de educación de la PUCE-Ambato; el fundamentar teórica y metodológicamente el desarrollo de la didáctica virtual en el desempeño académico de los estudiantes y diagnosticar en los maestrantes de educación la verificación del desempeño académico estudiantil para evaluar la didáctica virtual en el desempeño académico de los estudiantes de las maestrías de educación de la PUCE-Ambato. 


\section{MÉTODO}

El método utilizado en el artículo es de revisión descriptiva ya que describe estudios bibliográficos sistemáticos, que detallan a la didáctica virtual y desempeño académico en estudiantes de maestrías, facilitando a los lectores un abanico de teorías existentes para un análisis cualitativo resaltando la importancia de revisiones teóricas de autores para el desarrollo científico del tema, con el fin de exponer proposiciones para que el lector realice un meta análisis y discusiones de teorías, en cuanto a la estructura y los aspectos que se tienen en cuenta para valorar su calidad los 60 artículos citados dentro del estado de arte es el respaldo de análisis y discusiones a los descriptores, dirigiéndonos a bases de datos científicas como revistas indexadas, Scielo, Redalyc, dando confianza al artículo al considerar científicamente opiniones fiables y validadas, las palabras claves de búsqueda han sido encontradas como la didáctica virtual, el desempeño académico en maestrantes, educación superior on-line en momentos de pandemia.

\section{DESARROLLO Y DISCUSIÓN}

\section{Desempeño académico}

Desempeño académico significa descubrir que a través de la educación y la formación de las personas se transforma cada etapa de la vida, fundamentados en valores axiológicos que le brindan mayor fortaleza al conocimiento, capaces de convertirlos en buenos estudiantes y buenos ciudadanos. La educación forma y encierra todo lo que corresponde a la parte humana, lo impulsa al desarrollo y al engrandecimiento de la sociedad. Se lo considera también como un desarrollo en la construcción de conocimientos que el estudiante adquiere, para formar un conjunto de respuestas que lo acompañarán en el desenvolvimiento de las actividades cotidianas en su entorno, es decir se fortalece con las experiencias adquiridas $\mathrm{y}$, ello le ayudará a convivir de una forma abierta y responsable con la sociedad (Pardo, et.al. 2020).

Dentro del proceso educativo el desempeño académico en un estudiante guía el panorama hacia dónde quiere llegar. La variedad de actividades como el horario a clases, las planificaciones, creación de estrategias, que se realiza dentro del tiempo dedicado a los estudios marca un rumbo en el desempeño académico. Este conjunto de actividades muestra el camino que se debe seguir para alcanzar las metas propuestas dentro de su proyecto de vida; de acuerdo a ello el estudiante descubre la satisfacción que se logra al conseguir sus propias metas, porque conoce el tiempo y esfuerzo que ha dedicado a sus estudios, ello genera estímulos o desmotivaciones, de manera que puede reforzar la motivación personal o auto desmotivarse en el camino a sus proyectos (Parra, Tobón, y López, 2015).

Para ello, es necesario que un estudiante descubra el valor que tiene el desempeño académico, porque le permite conocerse a sí mismo y concientizarse en la fortaleza que tiene sus actividades de estudio, lo involucra en lo que corresponde al trabajo cognitivo, es decir en el desarrollo de sus propios conocimientos capaz de medir los objetivos alcanzados en el transcurso de la vida académica. Para enmarcarse en una buena educación con responsabilidad es necesario que se le ayuda a tomar conciencia de la convicción de servir a una sociedad con compromiso, por ello un buen desempeño académico es necesario por la responsabilidad que esto conlleva. La vida siempre está 
compuesta de retos y desafíos, de anhelos y sueños, de aspiraciones y nuevas ideas; para ello la persona debe buscar un buen desempeño en el paso por las aulas que, con esfuerzo y constancia se puede alcanzar las metas esperadas (López, Pérez, y Díaz, 2020).

Un alto nivel académico se lo considera como un éxito alcanzado en la escuela, luego transportado al trabajo y, a sí continúa su camino. En ello se requiere del desarrollo de habilidades, destrezas, hábitos, ideales, aspiraciones, intereses, inquietudes, realizaciones que, el estudiante pone en juego para aprender, esto es un conjunto de fortalezas que se requiere para conocer el nivel de aprendizaje alcanzado en las aulas de clase. Se debe resaltar que el rendimiento académico no solamente depende de los conocimientos de un estudiante, sino también de factores externos como la familia, el trabajo, el entorno social y, otros factores que rodean al individuo, esto causa una seria influencia en el aprendizaje adquirido $\mathrm{y}$, el resultado se expresará en los puntajes y notas logradas. Los nuevos conocimientos obtenidos realizan un trabajo autónomo de transformación de ideas y de la misma persona en su integridad, porque el conocimiento genera un nuevo mundo dentro y fuera de su entorno vivencial (Guzmán, y Ortiz, 2019)

\section{Desempeño académico en estudiantes de maestría}

Cada etapa en una persona tiene múltiples desafíos en todos los campos, vamos a ubicarnos en el campo académico $y$, dentro de ello las etapas de los estudios, que es aspirar a alcanzar algunas metas $y$, en un estudiante es llegar a una maestría y doctorado. La maestría como cuarto nivel presenta diferentes desafíos en el desempeño académico, es poner en evidencia a través de indicadores cuantitativos expresados mediante calificaciones y, mostrar sus conocimientos en un área o en una materia; sin embargo el desempeño académico no solamente se mide de una forma cuantitativa por numeración sino, de una manera integral, en donde se pueden obtener resultados no solo cuantitativos sino también cualitativos, que le permita al docente tener un enfoque global en pertenencia, calidad educativa y equidad al momento de ejercer una calificación, así; no se encaminará al estudiante solamente a la memorización de conceptos sino, también sus habilidades en un mundo laboral competitivo, ello ayudará a conocer el desempeño estudiantil en una forma integral (Contreras Álvarez, 2018)

El perfeccionamiento en los estudios superiores como maestrías, diplomados, doctorados y otras, expresa el interés que tiene un estudiante en desarrollar sus conocimientos para adquirir una mejor organización en su mundo laboral, profesional y familiar, porque las obligaciones son diferentes en cada estudiante, para ello debe adquirir mayores técnicas y hábitos de estudio que le ayudará en el desarrollo de la creatividad y organización. Es necesario invertir en libros y tecnología, porque el leer e investigar es parte básica para el desarrollo académico en todos los niveles educativos y mucho más a nivel superior; otra técnica a desarrollar es el escribir, esta técnica potencia todo lo que significa plasmar en el tiempo lo que se descubre y lo que se piensa; con ello se va a desarrollando mayores habilidades en la lectura y escritura para la redacción de artículos, revistas, libros, textos, entre otros (Mondragón, Cardoso, y Bobadilla, 2017).

El rendimiento académico tiene mucho que ver con el apoyo familiar y social, también de acuerdo a la especialidad que el estudiante elije por ejemplo, en Medina encontramos en 
un estudio realizado por Campillo, et.al. (2019) este documento manifiesta que de acuerdo a las investigaciones realizadas, son las mujeres las que más reprueban en esta carrera, puede ser por el desempeño de esposas, madres, profesionales, amas de casa $\mathrm{u}$ otras actividades; las madres de familia son las que más trabajan dentro y fuera del hogar y llevan mayor responsabilidad en todas las actividades que realiza una familia, quienes se merecen un saludo especial por la dedicación en todas sus actividades. En el caso de los varones son los que disponen de mayor tiempo y esa misma responsabilidad autogenerada como protector de un hogar hace que le dediquen mayores horas al estudio, encargando varias responsabilidades a sus esposas, como el cuidado y acompañamiento de sus hijos entre otras actividades. En este estudio que realizan los autores de este artículo se resalta y se quiere dar a conocer los porcentajes de abandono de las carreras profesionales en estudiantes.

El estudiante de maestría no solamente tiene la responsabilidad con el desempeño académico cuantitativo sino con todas circunstancias que los estudios conlleva, en el transcurso de la carrera se suscitan diferentes acontecimientos tanto familiares, sociales $\mathrm{y}$ laborales; para ello algunos centros educativos de alto rendimiento están modificando la forma de acompañar al estudiante para que no sienta la soledad en momentos de dificultad; para ello se están diseñando tutorías con profesionales de sus materias correspondientes $\mathrm{y}$, también con personal especializado en problemas sociales, de manera que en el proceso educativo el estudiante sienta que al centro educativo de estudios superiores no solo le interesa el enganchar estudiantes a la universidad, sino; que le interesa la persona humana que busca un crecimiento académico en conocimientos para realizar su aporte personal como profesional. (Chong, 2017).

El estudiante en cualquiera de las etapas necesita el apoyo profesional de los maestros de la universidad pero, también de su propia familia y el entorno social, es así que se pone en evidencia los resultados académicos en estudiantes que reciben apoyo en mayor porcentaje que otros; los que recibieron mayor porcentaje de apoyo también adquieren mayores resultados, es decir los recursos humanos y materiales son muy importantes al momento de encontrarse con resultados, porque siempre van hacer positivos, a ellos se les facilita la actividad educativa de una manera más amplia. En el otro grupo de estudiantes que tienen que pagarse sus estudios, que no disponen del tiempo necesario, que tienen una familia a su cargo $y$, que no tienen todos los recursos humanos y materiales a su disposición, ellos realizarán mayor esfuerzo para poder alcanzar sus metas estudiantiles, por la sencilla razón que no disponen de los recursos necesarios y, en ocasiones más difíciles es cuando tienen que abandonar su carrera cargada de sueños por falta de los recursos económicos (Cervantes, et. al. 2018).

\section{La educación virtual}

En Ecuador se declaró oficialmente el primer caso de COVID -19; el 29 de febrero del 2019, desde entonces la población entró en pánico; con el aumento exponencial de contagios, el presidente de la República del Ecuador, Lic. Lenin Moreno; anunció el estado de excepción para el Ecuador el 16 de marzo del 2020. Con ello se realiza un sinnúmero de cambios en la vida del ciudadano ecuatoriano, dentro de ello en el campo educativo que decidió suspender las actividades escolares a 
escala nacional en todos los niveles, desde entonces se ha realizado una transformación en las familias ecuatorianas al adoptar otra modalidad, la educación virtual (Aguirre, Zhindón, y Pomaquero, 2020).

El mundo de hoy presenta una gran facilidad para educarse, la educación en línea progresivamente ha ido ocupando un lugar importante a nivel mundial, ya desde décadas pasadas, la educación en línea encontró en la sociedad una gran oportunidad para posicionarse; su acogida se incrementó en este tiempo de la pandemia que expandió sus fronteras. La apertura que brinda la educación en línea en todos los niveles es inmensa, rompe esquemas tanto para maestros como para estudiantes. La educación en línea llegó para quedarse y acortar distancias, unir sociedades de todos los lugares de la tierra, juntó corazones altruistas que no tienen miedo a los nuevos retos en todo ámbito y en nuestro el educativo. La educación virtual ofrece la posibilidad de aprender de una manera más flexible y dinámica mediante materiales multimedia y videoconferencias. El desarrollo de todas estas nuevas herramientas virtuales ayuda al desarrollo de las destrezas de los estudiantes (Hernández, et. al. 2015).

La educación virtual facilita y brinda mayor apertura a los estudiantes para que se eduquen de todos los espacios geográficos, se rompan límites, espacios físicos y distancias; otro punto importante es la movilidad, porque ya no se necesita perder horas en el transporte como es en la educación tradicional; la educación virtual abre fronteras y es una gran oportunidad para que toda la humanidad pueda tener acceso eficiente a la educación desde todas partes del mundo. Es cierto que en algunos lugares es una limitación la conexión a la internet, también la saturación o baja calidad es otra de las debilidades en donde se está haciendo el esfuerzo necesario para que las empresas privadas puedan cubrir con este servicio en los lugares donde no se tiene alcance a la internet; junto a ello también las familias están realizando adquisiciones tecnológicas, como computadores, tabletas y teléfonos inteligentes, para aprovechar de mejor manera el uso de las herramientas tecnológicas en las clases virtuales (Núñez, 2020).

Es motivante conocer los avances que se van desarrollando en todos los campos de la ciencia, tecnología y educación; la educación va evolucionando permanentemente, no se ha estacionado para mirar desde lejos, sino que está en constante evolución, así ha pasado por adelantos importantes, desde los textos impresos en la imprenta, la aparición de la computadora como auxiliar del docente y estudiante, el teléfono portátil y un múltiple conjunto de herramientas tecnológicas que se van desarrollando frecuentemente, hasta que aparece la educación a distancia virtual. Países desarrollados como Australia, Nueva Zelanda, Estados Unidos de Norteamérica y Reino Unido, han sido pioneros en este tipo de educación virtual, dando apertura a todas las personas, ampliando y enriqueciendo la cultura del estudiante. Así se crearon las escuelas virtuales en todo el mundo y hoy es una de las herramientas más importantes para llegar con la educación virtual porque no tiene un horario fijo y permanente, no se necesita espacios físicos, la gran inversión en textos va desapareciendo, el ahorro de tiempo en las traslados de un lugar a otro hasta llegar a los centros educativos; la educación virtual acompaña en mejorar la investigación y al ahorro de recursos de todo tipo (Briceño, et. al., 2020). 


\section{Educación a nivel superior}

La educación superior se llama al proceso de formación post secundaria que lo contempla cada país en su sistema educativo; este se imparte en las universidades, academias superiores y otras instituciones de nivel superior. La continuidad en la educación superior permite que el estudiante desarrolle mayores habilidades, destrezas y competencias a base del conocimiento. A nivel global es necesaria la educación superior para la investigación y desarrollo de los países. A fines del 2019 con la aparición de COVID-19, la educación superior también sufre un cambio, en donde se traslada de una educación tradicional presencial a la educación virtual a distancia. A nivel presencial se generaba límites de estudiantes por aula, ahora a nivel virtual no se debe considerar las limitaciones por aula, sino más bien ampliar el nivel educativo y tratar de llegar a los rincones de las poblaciones más olvidadas. (Ordorika, 2020).

La forma de educar en las universidades definitivamente ha tomado cambios importantes, porque al cambiar de modalidad presencial a virtual obliga al docente a prepararse con mayor dedicación en uso de las herramientas tecnológicas, en lo didáctica, pedagógico y en la mejora sus competencias al compartir su horario de clase. Las universidades continúan diseñando nuevas formas de educar, evaluar y acompañar al estudiante dentro o fuera de su país. La falta de garantías que genera esta pandemia hace que miles de estudiantes hayan regresado a sus países de origen y no puedan estudiar presencialmente como fue su deseo; a escala mundial ha causado un fuerte impacto emocional, porque no todos los países estaban preparados para llevar una educación virtual, especialmente en América Latina que no tiene acceso a internet en todos los rincones de sus países; es por ello el abandono de estudiantes a la educación en todos los niveles ha sido masivo. A nivel superior tomó por sorpresa a los estudiantes y docentes que en su mayoría no hacían uso de las herramientas tecnológicas que es necesario para la educación virtual (Guerra, 2018).

La educación virtual y falta de internet en la mayoría de los hogares en Ecuador, se ha convertido en un dolor de cabeza, por lo que la contratación de estas nuevas herramientas tecnológicas no constaba como egresos económicos dentro de rubros familiares, a ello se le suma la compra del computador, teléfono inteligente y otros accesorios tecnológicos, ya que son recursos necesarios en todos los niveles de la educación virtual. Por ello es un desafío para los gobiernos de turno cubrir con esta deuda social y tecnológica (Briceño, et. al. 2020).

Los planes curriculares deben cambiar, la realidad educativa es diferente a la que se estuvo acostumbrado, las necesidades son otras, ojala el Ministerio de Educación, se acerque a la realidad escolar de todos los niveles y realicen algunos ajustes indispensables como los contenidos y materias en las que se continúan dictando los mismos contenidos de hace 50 años atrás; la forma de llevar una educación innovadora debe ser eficiente y actualizada a las necesidades globales que gritan por cambios urgentes en el sistema educativo mundial y nacional. Quedó atrás el enciclopedismo, el memorismo y otras metodologías atrasadas de evaluar, que no son las únicas que ayudan al estudiante a generar conocimientos sino, que existen diferentes formas de ayudar al alumno para que conozca nuevas fuentes de conocimiento e información (Alcántara, 2020). 
Es necesario abrir nuevos paradigmas mentales en el campo educativo, para aquellos que llegan a ocupar un puesto en el gobierno, para buscar e incorporar nuevas formas de hacer educación, tomando como ejemplo países que han desarrollado su potencial integral a través de la educación superior como Singapur, Japón por nombrar; los nuevos modelos en educación son primordiales $\mathrm{y}$ necesarios para el crecimiento y, un mejor futuro para las próximas generaciones que necesitan de la responsabilidad de los gobernantes. La investigación se desarrolla con una guía establecida a largo plazo como ya lo demuestran algunos países que ocupan los primeros lugares en investigación, entre ellos la China, Japón y otros que, a base de reformas y políticas educativas a largo plazo e inversión en educación han podido despegar $\mathrm{y}$ posicionarse a nivel mundial (Xu y García, 2021).

El abandonar la investigación y no darle importancia a la educación en todos los niveles y especialmente a la educación superior hace que una sociedad vaya muriendo lentamente porque no incrementa sus fuentes de desarrollo, fuentes de trabajo, su capital humano, no tiene la capacidad de producir y desarrollarse como persona en su entorno familiar; por lo tanto, la sociedad no tiene como crear trabajo y recursos, esto lleva a aniquilar las esperanzas de una sociedad. La educación superior y la selección de las carreras profesionales de acuerdo a la necesidad del país es primordial e importante porque de ello dependerá el desarrollo de un pueblo (Xu y García, 2021).

El desarrollo de la ciencia y tecnología en la educación superior marca un camino de crecimiento en una casta, ello te encamina a formar valores como el compromiso, responsabilidad y amor al servicio de la humanidad; una sociedad educada practica mejor los valores, no solamente mira por sí mismo, su mirada está en los demás que necesitan formar una alianza, un engranaje, estrechar lazos perdurables que reafirme y siembre un futuro en el desarrollo social y económico de un pueblo. La ciencia, la industria e ingenierías tecnológicas se han desarrollado a través de la historia con el apoyo de la educación superior, por ello las universidades desempeñan una función vital en la formación de profesionales que aporten al desarrollo y crecimiento de un país (Xu y García, 2021).

Los presupuestos para la educación superior en países en desarrollo no es alentadora, porque la inversión que deberían realizar no cubre las necesidades requeridas para la investigación pero; sin embargo, este nivel educativo ha experimentado diferentes cambios y transformaciones, en donde se ha observado $y$ se ha vivenciado grandes esfuerzos que han realizado las autoridades y el estado en invertir en infraestructura que necesitaba del mantenimiento y amplitud de los espacios físicos, también el mejorar los pocos laboratorios existentes, (Xu y García, 2021) todo ello ayuda para que el estudiante de educación superior desarrolle sus capacidades intelectuales, habilidades $\mathrm{y}$ destrezas. Me encantaría llegar con este artículo a los encargados de los ministerios de educación para que se concienticen en la potencialización que tiene la educación virtual y el avance que tiene al no cerrar fronteras o preocuparse por los espacios físicos de los que siempre fue el principal problema de las universidades. Ojalá con la llegada de esta modalidad educativa se abran las posibilidades a los jóvenes que desean estudiar (Ruz, 2021). 


\section{Complejidad de la educación virtual en un estudiante de maestría}

Hablar de complejidad es hablar de nuevos desafíos con innovación educativa que una persona adquiere $\mathrm{y}$, en el campo de educación superior específicamente de maestría, el estudiante acepta el compromiso de adaptarse a la modalidad virtual; cierto que se desconoce las herramientas a desarrollarse, pero, el propósito es mirar hacia adelante y avanzar en los estudios superiores. Se torna complejo esta modalidad por el motivo que no se tiene la cercanía del maestro o del compañero estudiante para compartir el tipo de programa o el uso de herramientas nuevas que van apareciendo, en ello se ha generado el sentimiento de soledad y desánimos, pero; el camino y la mirada a la meta se debe continuar; en esta modalidad de educación se han incorporado un sinnúmero de instrumentos tecnológicos que vienen en uso, al no existir la práctica necesaria en ellas, se genera pánico por lo desconocido (Mogro, 2020).

Esta nueva modalidad virtual tiene la finalidad de acercarnos y no alejarnos, más bien acorta las distancias y promueve el aprendizaje sin límites, como la ubicación, edad, ocupación, tiempo; para ello el estudiante necesita mayor esfuerzo y sacrificio en lo que concierne a la planificación y organización de su horario para el estudio. Las tutorías o el material didáctico es necesario para que el estudiante disponga de los avances correspondientes en las programaciones y cronogramas establecidos; para ello es importante la participación y acompañamiento del docente que se convierte en el facilitador y asesor, con un conocimiento y dominio de la tecnología, esto permitirá que el alumno pierda el miedo de continuar y aceptar el desafío en llevar este tipo de educación (Sanabria, 2020).

Hoy los alumnos de todos los niveles llevan en sus rostros la melancolía de no tener la facilidad de compartir las clases de una manera presencial, pero en los estudiantes de maestría no sucede lo mismo, porque la organización de su horario de actividades es diferente, cada uno tiene su trabajo, familia, hijos, negocios; más bien al estudiante de maestría se le facilita las actividades, se dispone de mayor tiempo, mejor organización y disponibilidad para acudir al horario de clases, con ello se evita ahorro en la movilidad, en lo económico y otros aspectos que favorece esta modalidad. Es cierto que toma tiempo disciplinarse y motivarse porque se necesita mayor compromiso y responsabilidad para dedicar mayor tiempo a la investigación, desarrollo de las tareas, y, así mejor su autoaprendizaje (Aguirre, Zhindón, y Pomaquero, 2020).

La necesidad de la educación virtual sigue creciendo aceleradamente a causa de la pandemia en donde no se presentan otras alternativas, los estudiantes de todos los niveles que todavía no tienen acceso a la internet buscan y acuden a lugares a donde pueden hacerlo; todavía existe en Ecuador los centros privados de computación, que son los que prestan sus servicios a estudiantes de todos los niveles e incluso de nivel superior y maestría; es una de las dificultades más graves que los estudiantes están pasando en este momento y, que no es posible solucionarlo porque no existe acceso a la internet en los lugares lejanos. En verdad la educación virtual ha creado una incomodidad difícil de solucionar, pero, fácil de exigir para las autoridades del Ministerio de Educación y, los responsables de todos los centros educativos que poco pueden hacer para la continuidad y 
acompañamiento de sus estudiantes (Aguirre, Zhindón, y Pomaquero, 2020).

Una de las dificultades que se observaron a nivel mundial en los centros educativos de todos los niveles es la improvisación de la enseñanza en esta modalidad, porque no estuvieron preparados, aunque a sus estudiantes les exigen continuar con sus respectivas clases; se observó que algunos de los profesores aplicaron simplemente la buena voluntad, otros aplican modelos de clase presencial; por lo tanto es urgente la necesidad no solo para el estudiante sino para el docente realizar una capacitación tecnológica adecuada en el conocimiento del uso de las herramientas tecnológicas desconocidas $\mathrm{y}$, que en otros países ya son obsoletas; con el propósito de facilitar la construcción del conocimiento en los estudiantes (Mesén, 2020).

¿Están preparados los centros educativos para transmitir los conocimientos a través de la educación virtual? Es importante esta pregunta porque nos permite reflexionar acerca de la realidad escolar de nuestros hijos, los que se sienten perjudicados en los horarios de clase, ya que han reducido el tiempo de la hora clase y las horas semanales de enseñanza; entonces es urgente que las autoridades revisen si se está llegando al estudiante con los contenidos deseados; aunque algunas ya se están olvidando que la pandemia continua y aspiran con urgencia volver a las aulas físicas, según ellos para potenciar y dedicar mayor tiempo a los alumnos (Guerra, 2018).

\section{Docentes y estudiantes de maestría en tiempos de pandemia}

Uno de los momentos catastróficos para la humanidad de estos últimos tiempos es la pandemia que se desató a nivel mundial a finales del 2019, este año quedará en la memoria de la historia en donde nacieron profundos cambios. Al rededor del mundo se creó gran tensión y el estrés al observar en los medios televisivos como las personas fallecían, y se desplomaban en las calles, aceras, en las casas de salud. Esto trajo consigo un sinnúmero de cambios en los servicios diarios y en los que promueven el desarrollo del país; así la educación dio un giro verosímil tanto para estudiantes y docentes (Oropeza-Amador, Hernandez-Aguirre, y Reyes-García, 2021).

Estos momentos conlleva un gran desafío para todos, de convertir la tristeza en oportunidades creadoras, tomándose el tiempo necesario para pensar, organizar y buscar alternativas de solución en todos los campos pero, de manera especial en la creatividad para compartir la educación haciendo uso de todos los medios posibles que se tiene al alcance, con ello no dejar afuera a ningún estudiante, no es tiempo para separar a ningún alumno de ninguno de los niveles por falta de herramientas tecnológicas, inclusive por falta de pagos en las pensiones, es urgente desarrollar la creatividad y, si es posible hasta visitarlos personalmente para compartir el material correspondiente para que los escolares continúen realizando sus cursos respectivos $\mathrm{y}$, no se desanimen por ninguna de las circunstancias presentadas. Es necesario que el docente se convierta en un motivador, debe ser un amigo que aprendió a comprender la realidad que no es igual para todos, algunos gozan de la presencia de sus padres y familiares, otros lo han perdido todo (Briceño, et. al., 2020).

El estudiante de maestría también desempeña el rol de docente, esposo, padre de familia y, en este tiempo de pandemia no ha tenido el acompañamiento del Estado como un actor motivante y capacitador sino, más bien con persecución y agostamiento por tanta documentación insignificante para el control 
del docente, ello trae consigo cansancio, desmotivación, agotamiento y desgano al momento de compartir el rol de docente. Como castigo por parte del gobierno ecuatoriano hubo un recorte de sueldo por seis meses, sin tener compasión de que el maestro es estudiante, padre de familia, esposo y que se esfuerza por aprender para compartir mejores conocimientos a sus alumnos. Es que al existir dentro del ministerio educativo personal de cuotas políticas que desconocen la realidad educativa del país en sus diferentes regiones, eso hace que tomen decisiones equivocadas y se escuden en solicitar documentación permanente de las planificaciones. Se debe valorar el esfuerzo, valentía y deseos de contribuir con una mejor educación al país con su inversión en educación, a la que aplaudo la mentalidad triunfadora que llevan estos maestros que siguen capacitándose cada día para engrandecer su patria (Ruz, 2021).

Dentro de la problemática que lleva el docente y estudiante en sus hombros no es solamente la modificación de las clases que imparte virtualmente sino; la imposición de contenidos y evaluaciones que se les ocurre a las personas que temporalmente ocupan un cargo de alto rango y que se olvidan de contribuir a la educación; eso no es innovación, más bien es retraso a la educación; es urgente que personas que ocupan estos cargos altos en formación tengan la preparación y experiencia necesaria, con la enseñanza no se puede improvisar, no se puede estancar y mucho más, no se puede retrasar, estas personas que pasan por estos cargos no tienen conciencia de lo mal que hacen a un país, al desconocer cómo se hace educación y que reformas profundas se necesita para dar un salto al progreso a través de la instrucción. La esclavitud no ha terminado, se la disfrazado con otros sometimientos desde los mismos gobiernos de turnos, en todas las instituciones solo nos hemos convertido en esclavos modernos (Oropeza-Amador, Hernandez-Aguirre, y Reyes-García, 2021).

\section{Evaluación en educación superior virtual en los estudiantes de maestría}

Desarrollar cada día los conocimientos dignifica a una persona, es continuar viviendo, porque existen muchas formas de morir y una de ellas es dejar de conocer, descubrir y alimentarse de nuevos conocimientos; a través de la historia se han marcado ciertos estereotipos de culturas dominantes como por ejemplo, el crear un gran ejército para defender su territorio, ser productor de alimentos para proveer a otras sociedades, tener gran armamento para someter a sus pobladores, o desarrollar conocimiento para generar investigación y a través de ella desarrollar una sociedad fuerte, creativa e innovadora para hacer de la vida menos complicada; por ello en los centros educativos de todos los niveles de un estado no se debe imponer tipos de evaluaciones, al contrario deben preocuparse por desarrollar formación, conocimiento e investigación a los docentes, porque ellos son los comunicadores de la ciencia, ellos son el arma que no causan daño a las personas sino que las dignifican y les ayuda a desarrollar un mejor porvenir en sus vidas a través de sus enseñanzas (Estrada y Fuentes, 2021).

Los gobiernos de Latinoamérica se han convertido en expertos manipuladores de la educación, seguro que el desarrollo de las naciones no les interesa, por ello no realizan la inversión necesaria que se requiere, les interesa que su pueblo sea ignorante para seguir manipulando y comprándolos con ideas mal formadas, con migajas y bonos que empobrece a los pueblos; esto debe 
terminarse, piensan que cuando llegan al poder se convierten en dueños de una hacienda, por ello no invierten en capacitación a los docentes, no realizan un cambio en los contenidos de las asignaturas, se manipula y ejercen presión con las evaluaciones a los docentes como signo de presión; pregunto $i$ qué es lo que desean evaluar? ¿A quiénes de los llegan a ocupar un cargo público les interesa el desarrollo de la ciencia, tecnología y alta ingeniería? Para llegar a este punto importante como es la evaluación a docentes y a estudiantes de maestría o doctorado, primeramente, debe existir coherencia de un Estado que debe capacitador a los encargados del Ministerio de Educación, luego capacitar a los docentes y después evaluar a los estudiantes (Pardo, et. al., 2020).

Debería existir una verdadera evaluación en la educación superior para que ello lleve a la investigación y, la investigación conduzca a la producción de ciencia y alta tecnología, porque todo es un hilo conductor que guía y encamina a grandes resultados; es cierto que las universidades evalúan de acuerdo a la forma que ha aprobado la Senescyt, pero esa forma de evaluar quedó congelada en la historia, porque no tiene nada de innovador; este tipo de evaluaciones se lo viene realizando por décadas, se debe recordar que los conocimientos van cambiando, todo va innovando $\mathrm{y}$, parece que en educación el tiempo se ha inmovilizado. Evaluar es darle importancia al sistema educativo, no dejarlo que camine solo, el detalle está en que no se puede evaluar cuando no existe constante capacitación (Estrada y Fuentes, 2021).

Dentro del proceso de enseñanza las universidades realizan todos los esfuerzos por formar en sus aulas estudiantes activos, creativos y receptivos que los encaminan a verificar los resultados propuestos en el módulo, acompañado de los métodos de evaluación sumativa y formativa, ello les lleva directamente a vivir una experiencia y una conexión con la sociedad, para evaluar si se está aplicando el desarrollo de las habilidades y competencias que se habrían propuesto dentro del programa universitario; dentro de ello se realiza una evaluación de aspectos básicos para iniciar como la conectividad, tipo, tecnología, cobertura, todo esto para tener una mirada de los aspectos positivos y negativos de la educación virtual (García, 2021).

Toda institución necesita realizar permanentes evaluaciones, con mayor frecuencia debería realizarse en la educación de todos los niveles, pero; más que evaluar se debería enseñar, formar y transformar vidas. Uno de los tipos de evaluación que personalmente me agradan es la formativa, porque trata de proporcionar una formación continua y permanente tanto al estudiante como al docente, de corregir errores $\mathrm{y}$ falencias, de guiar y potencial; es decir crear un intercambio de conocimientos $y$, una profundización en lo que se desea continuar investigando, todos los tipos de evaluaciones necesitan cuidadosos métodos, que no se deben separar a la una de la otra. Dentro de las formas de evaluar está también la personalizada, que es satisfactoria o insatisfactoria; es decir la satisfacción personal, para ello se necesita un alto nivel de criterio en formación y alta formación; todos estos métodos evaluativos ayudan al final a desarrollar y adquirir un mejor alumnado (García, 2021).

\section{Problemas bio-psicosociales que se adquieren en educación virtual}

Los cambios siempre generan nuevas expectativas y mucho más si llegan de una forma inesperada y a presión, eso fue lo que 
sucedió con la aparición de la educación virtual y el teletrabajo en un docente, los problemas psicosociales fueron apareciendo rápidamente, se lo conoce como el síndrome de Burnout, que es una manifestación aguda de estrés laboral enfocado en cuatro puntos: con el estudiante, lugar institucional, docente y estrés laboral; es decir son las condiciones en donde se realiza la labor de trabajo, todo esto genera malestar y preocupación en la actitud de los maestros por el desgaste permanente psicológico, personal y familiar que esto genera; porque sus labores no solo se extienden al horario que estaba establecido cuando se trabajaba de forma presencial, sino que se ha duplicado en atención a estudiantes y padres de familia, a ello adjuntamos el aprendizaje y la autoformación para trabajar en las plataformas y herramientas tecnológicas que son nuevas para el docente y estudiante (Mejía, Silva, y Rueda, 2020).

Uno de los problemas es la insatisfacción por el trabajo, no porque no tenga compromiso sino, por la tensión, presión y bombardeo de tantas responsabilidades que conlleva el teletrabajo con estudiantes, esto genera inestabilidad emocional y un estrés silencioso que va transformando el comportamiento de una persona que lo lleva a actuar de una forma negativa, generando cambios en su conducta, incluso con deseo de abandonar o cambiarse de trabajo. También se crea fatiga mental, baja autoestima, desmotivación; esto lleva a una disminución en el desarrollo de la capacidad laboral, bajando el nivel y atrayendo los retrasos en las obligaciones de docente, porque su enfermedad silenciosa causada por el estrés no le permite continuar con el desempeño normal de sus actividades; estas son la nuevas dinámicas que se va desarrollando en este tiempo de pandemia, en ello como principal ayuda debe estar presente la familia para apoyar y ser el soporte y motivación (Ruz, 2021).

La docencia conlleva a un encierro permanente de por lo menos ocho horas diarias, como resultado de ello aparece la ansiedad de no poder compartir de manera física con los compañeros y estudiantes en la institución, el sentirse solo, cargado de tareas y reuniones virtuales, atención a padres de familia, ha causado en los docentes una ansiedad que encamina al consumo de tabaco, exceso en la comida, trastornos mentales, enojos en la familia $\mathrm{y}$, en algunos casos consumo de alcohol; otro de los problemas causados es también los dolores permanentes de cabeza, cuello, espalda, hombros, que se han quedado para vivir en sus cuerpos, porque mientras no se cambie esta modalidad de estudio es muy difícil abandonar y despegarse de estas dolencias que se han convertido en los peores compañeros del trabajo de un docente (Mejía, Silva, y Rueda, 2020).

La educación virtual ha sometido a estudiantes y docentes a una permanente automatización de actividades, en donde las ocho horas de trabajo están en una posición que no es ergonómica en su totalidad, lo cual se desencadena en problemas lumbares; esta automatización laboral no solo afecta en el cansancio mental a los docentes, sino también a los estudiantes, que en conjunto están adquiriendo estrés y cansancio mental; la sobrecarga laboral encamina a un sobreesfuerzo mental, a tal punto de caer en una monotonía y aburrimiento; la falta de interacción física es factor muy importante en el desarrollo de las actividades laborales, obviamente por falta de costumbre en el trabajo. Generalmente las personas se acostumbraron a compartir físicamente sus horas de trabajo, a interactuar sus experiencias, a convivir con los sonidos 
agradables de sentir que existen personas a su alrededor con quien puedes interactuar en cualquiera de los momentos que lo necesitas (Torres, 2020).

Para buscar algún tipo de descargo o alivio a los problemas generados por el estrés laboral producto de la educación virtual, se sugiere la ayuda de la permanencia de un psicólogo dentro de la institución como medio para ayudar a sus compañeros de trabajo, también a realizar algunos tipos de terapia como yoga, un horario diario de deporte, crear espacios de relajación por lo menos cada hora; estas actividades diarias ayudarán tanto a estudiantes como a docentes a bajar la intensidad del estrés laboral que es inevitable en este tiempo de pandemia y, que a toda persona le ha causado algún agobio. Se debe resalta que no solo ha traído problemas y complicaciones la educación virtual sino, que también ha traído soluciones a la movilidad, al aprovechamiento del tiempo, al ahorro de recursos y, a la facilidad para trabajar desde casa (Torres, 2020).

\section{Didáctica virtual}

La didáctica virtual se ha convertido en un nuevo espacio de aprendizaje tanto para el docente como para el alumno, así como limita la cercanía entre las personas, también brinda apoyo a todos, tanto al que transmite los conocimientos como al que aprende. La virtualidad denota un espacio educativo con características propias que benefician la aplicación de las estrategias de enseñanza aprendizaje. Se busca sacar el mayor provecho a la internet para recuperar el contacto, aunque sea a distancia entre tutores y los estudiantes de maestría (Suárez, 2010). Por otro lado, la didáctica se establece en base al acto educativo $\mathrm{y}$ por medio de las interacciones comunicativas lo que le engrandece; la misma es entendida como una disciplina pedagógica aplicada, esto se refiere a la práctica de teorías pedagógicas (Saza, 2016).

Teóricamente se conoce a la didáctica como el conjunto de teorías de enseñanza; por lo tanto, es importante construirla en referencia a los escenarios y problemáticas que en ellas surgen y ocurren (Jaramillo, 2015). A su vez, es una disciplina que se caracteriza por su objetivo formativo y su aportación en los diversos modelos, enfoques $\mathrm{y}$ valores intelectuales adecuados con la finalidad de organizar las decisiones educativas y realizar avances en el pensamiento, también es base de la enseñanza y el desarrollo crítico y reflexivo del saber cultural y artístico en los distintos contextos (Medina y Salvador, 2009).

Los nuevos aportes tecnológicas y la implementación de las TIC en el saber didáctico, posibilita un proceso de formación académica adecuada, planificada y ajustada al análisis de las necesidades y contextos formativos, pero si no se conoce la manera adecuada de crear estos espacios virtuales, tanto docentes como estudiantes de toda índole podrían perderse, mucho más si los educandos son personas adultas que no han tenido relación con la didáctica virtual. Esto podría causar varios problemas en la difusión de conocimientos pues si bien es cierto que en la formación del alumno se debe cumplir los objetivos propuestos (Ortiz, Santos, y Rodríguez, 2020).

Dentro de la didáctica se encuentra el proceso de enseñanza y aprendizaje que debe permitir la impartición de conocimientos de forma efectiva, profunda y significativa, al tener lugar con la utilización de las tecnologías de la información y la comunicación, el docente debe diseñar estrategias para fortificar las experiencias de aprendizaje para los estudiantes de cualquier nivel $\mathrm{y}$, en este 
espacio los alumnos de maestría en educación. Además, de brindar satisfacción $\mathrm{y}$, por consiguiente, la permanencia en el curso o en el programa impartido de la nueva modalidad online. (Salgado, 2015).

Las tendencias didácticas son un conjunto de posiciones teóricas pedagógicas que se clasifican en clásicas, tradicionalistas e innovadoras. Las mismas radican en la concepción del acto didáctico y su finalidad se centra en el proceso instruccional; se considera que el docente es el sujeto principal que genera un aprendizaje receptivo (Pando, 2018).

Las prácticas didácticas que el docente aplique es para promover el aprendizaje y adaptarse al entorno en el cual se encuentran $\mathrm{y}$, si es necesario realizar cambios radicales y mucho más si se da en situaciones repentinas. El solo hecho de impartir una asignatura o curso en la modalidad online es innovación, si bien es cierto altera significativamente el proceso educativo para los docentes como para los estudiantes de maestrías, que en su mayoría no han tenido un acercamiento a las nuevas tecnologías y, el cambio de soporte digital puede ser un arma de doble filo (García, 2017). Para una correcta aplicación de la didáctica y todas las dimensiones que la complementan en este caso la virtual, se debe elaborar y planificar un proyecto de manera adecuada, para ello resulta importante disponer de un modelo y una metodología que sirva como base para el éxito de didáctica y educación virtual (Marciniak, 2017).

El uso de la didáctica virtual con las nuevas tecnologías se ha convertido para la comunidad educativa en la culpable de los diversos cambios para la sociedad y, varias veces se la tilda de deshumanizante puesto que ha separado la comunicación presencial personal. Es de suma importancia la planificación y diseño del proceso de enseñanza - aprendizaje en el ambiente virtual, ajustadas a teorías, principios $\mathrm{y}$ criterios basados en modelos pedagógicos fundamentados en la educación a distancia. A continuación, se presenta en la figura 1 los procesos que se debe realizar en la didáctica virtual. 


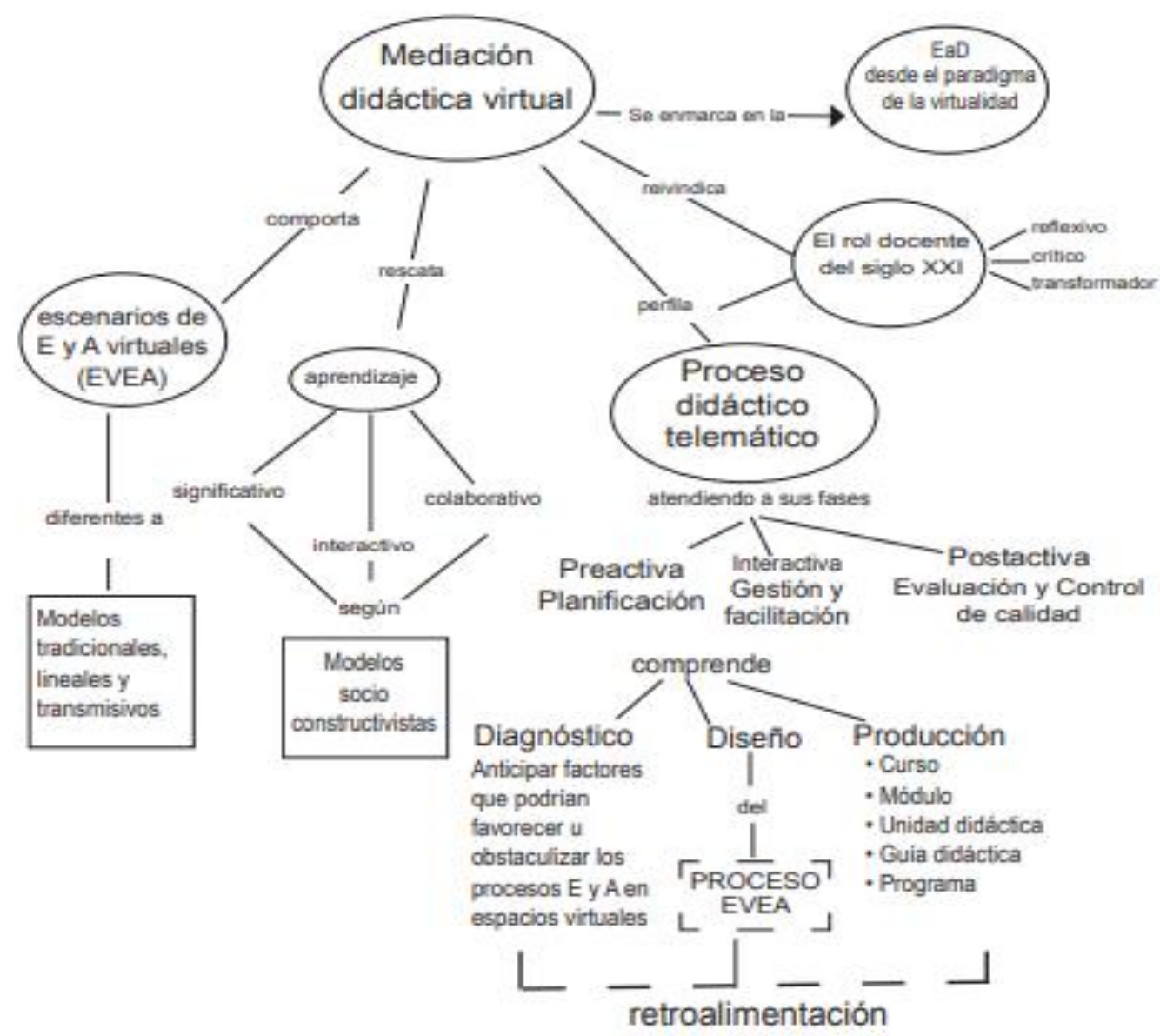

Figura 1: Los procesos de la mediación didáctica virtual

Los distintos factores externos llevan a la educación superior a crear una comunidad virtual, el mismo que involucra a un nuevo ambiente educativo en el cual el modelo tradicional se ha sustituido para que, el tutor sea un promotor de conocimiento para los estudiantes. El rol del docente es un factor clave pues su papel protagónico dará paso a la efectividad de la herramienta que se utilice (Calvo, et.al., 2019). Pues esto beneficiará o repercutirá en el desempeño académico de los alumnos

\section{Desempeño académico}

Los nuevos paradigmas emergentes por el contexto en el cual se encuentra el mundo, se basa en aplicar un proceso de enseñanza aprendizaje a través de la dinámica virtual que ayude a la adquisición de conocimientos y a su vez el educando siga teniendo el mismo desempeño académico (Rojas,et.al., 2014).

El desempeño académico en la vida de un maestrante influye en dos, la habilidad y el esfuerzo. Dentro de las dimensiones del desempeño académico, el proceso enseñanza aprendizaje trata de evaluar para identificar falencias y búsqueda de soluciones, con la finalidad de mejorar los factores que puedan ocasionar un bajo rendimiento (Edel, 2013). Pero antes, aclaremos ¿qué es desempeño académico?, proviene del latín "reddere" (restituir, pagar) se relaciona con el esfuerzo 
empleado para alcanzar $\mathrm{u}$ obtener los objetivos planteados. También se denomina como la aptitud escolar y, es el nivel de conocimientos demostrado por el alumno en una área o materia especifica comparado con el nivel académico e incluso con la edad (Quintero y Orozco, 2013).

El desempeño académico implica la calificación obtenida en los procesos evaluativos realizados por el educador, pero siempre está relacionada con un contexto definido para que pueda ser entendida y por otra parte significativa. Entendiendo que el contexto es el grupo de estudiantes al cual se dirige el curso y cómo hacer que se impliquen de manera activa. El mismo debe ser valorado por ciertos indicadores de desempeño que se enfocan en llamar la atención del alumnado en aspectos específicos de la materia. De igual forma estos indicadores son planteados por el docente como referentes de logro, los cuales son medibles y señalan que tanto han aprendido en el proceso educativo (Martínez y Heredia, 2010).

Para varios autores el desempeño académico puede clasificarse en dos grandes grupos: aquellos que la definen como sinónimo de aprovechamiento y los que señalan una gran diferencia de ello. El mismo puede demostrarse a través de calificaciones asignadas por el docente o un promedio de todas las notas acumuladas obtenidas por el estudiante que se observarán al final del año que resume su rendimiento (Palacios \& Andrade, 2017).

Algunos autores también manifiestan que el éxito de un buen desempeño académico en los estudiantes es tener un equilibrio en la parte académica, social y personal. Puesto que esto le permite al alumno tener un mayor manejo de sus tiempos y determinar los objetivos que desea alcanzar. Los mismos se logran a través de un trabajo conjunto de los tutores y educandos en torno a un proyecto común para la adquisición de conocimientos, habilidades, destrezas, hábitos y actitudes (Urquijo, 2010).

\section{Medición del desempeño académico}

Por lo general, el desempeño académico son los resultados logrados de los educandos en términos cualitativos o cuantitativos, los mismos posibilitan la relación con factores asociados a las variables psicológicas, demográficas, sociales y educacionales con la finalidad de describir los efectos de los resultados bajos $o$ altos. Una nota $o$ calificación, debe ser consistente y valida, pues es el reflejo del aprendizaje a través de los objetivos (Basto, 2017)

En educación y pedagogía el desempeño académico permite evaluar la eficiencia y la calidad de los procesos de enseñanza aprendizaje, siendo el resultado su labor como docente, convirtiéndolo en un indicador para la toma de decisiones (Suárez, Elías, y Zarza, 2016). Además, se puede tomar como una medida de las capacidades y habilidades que tiene el alumno sobre todo lo que ha aprendido del curso o materia, como resultado de los procesos educativos, siendo un indicador de aprendizaje adquirido, siendo el reflejo del esfuerzo, dedicación, conocimientos $\mathrm{y}$, en especial del logro de lo planificado (Isaza y Henao, 2012). En la actualidad al analizar el desempeño académico en los ambientes educativos virtuales se pudo determinar distintos factores que inciden en el mismo. 


\section{Factores que afectan el desempeño académico}

Existen diversos factores que se involucran en el desempeño académico que pueden estudiarse desde distintas perspectivas.

Tabla 1. Factores que afectan el desempeño académico

\begin{tabular}{ll}
\hline Factores fisiológicos & $\begin{array}{l}\text { Entre ellos encontramos: cambio hormonales, desnutrición, } \\
\text { problemas de salud, etc. }\end{array}$ \\
Factores pedagógicos & $\begin{array}{l}\text { Relacionados al ámbito educativo. Son métodos y materiales } \\
\text { utilizados, motivación del estudiante, tiempo dedicado a preparación } \\
\text { de clases en la virtualidad, poco uso de la tecnología. }\end{array}$ \\
Factores psicológicos & $\begin{array}{l}\text { Relacionados con funciones psicológicas básicas como: la memoria, } \\
\text { la percepción, etc. }\end{array}$ \\
Factores sociológicos & Factores familiares y socioeconómicos. \\
\hline
\end{tabular}

Fuente: (Izar, Ynzunza, y López, 2011)

En este caso nos adentraremos en los factores pedagógicos, psicológicos $\mathrm{y}$ sociológicos.

El confinamiento que ha ocurrido en todo el mundo ha tenido varias repercusiones en el ámbito educativo y más en el desempeño académico. Y que por el encierro y la nueva modalidad adaptada cada factor se relaciona formando varios problemas que detallaremos a continuación. Dentro de los factores pedagógicos el que más incide es la escaza capacitación de las nuevas tecnologías y su uso en la educación. Por la nueva modalidad adoptada por el confinamiento, los docentes han tenido que adaptarse lo cual ha generado varios desafíos en su uso adecuado y ha acentuado las brechas digitales, las mismas que marcan las desigualdades sociales $\mathrm{y}$ económicas de nuestro país (García, 2020).

El impacto del estado de contingencia ha afectado severamente la parte psicológica de todas las personas en el mundo que ha incrementado problemas en la salud mental, generando miedo, estrés, pánico, incertidumbre, entre otros (Robinet y Pérez, 2020). Los principales retos que se encuentran son la brecha digital y la accesibilidad. Si bien es cierto, los nuevos métodos han sido controversiales puesto que algunos docentes no conocían perfectamente su uso. A pesar de que es una manera efectiva de controlar y limitar la propagación del virus (CGLU, 2020). Además, el estado de contingencia ha sido un componente clave para desatar varios problemas psicológicos en los estudiantes de todo tipo en especial los de maestría.

\section{Motivación}

La motivación es una parte fundamental para el proceso de enseñanza y aprendizaje y mucho más cuando los estudiantes son profesionales que siguen educándose. Pues es un estado psicológico que se relaciona directamente con los estudios y de esta manera ayuda a asimilarlos de manera positiva y significativa (López y Estrada, 2010). 


\section{Ansiedad}

Por el confinamiento ha despertado en todos los seres humanos desde pequeños hasta los adultos episodios de ansiedad. Pues las cargas de estos pueden hacer que el alumno se perciba así mismo como incompetentes académicamente, por lo cual obtienen un bajo desempeño académico (Castellanos, et. al., 2017).

\section{Estrés}

Varias personas se han estresado por varios factores tales como: la propagación del virus, su estado económico, por el trabajo, entre otros. Que afecta de gran manera en la salud mental del estudiante (González, et.al., 2020).

\section{Depresión}

Muchas veces se asocia a la depresión con el desempeño académico, y se vincula directamente con la autoestima y la autocrítica que se forja desde la etapa infantil y persiste hasta la adultez. El confinamiento ha elevado los problemas emocionales y de conducta. Por ese motivo es importante hablar de ello (Pérez y Urquijo, 2010). Los factores sociológicos también han sido influenciados por la pandemia, entre los más fundamentales se tienen:

\section{El Contexto familiar}

Como bien se sabe la familia es el núcleo de la sociedad. Actualmente, por el estado de contingencia la familia ha sido afectada tanto por el encierro como por sus miembros que han sido infectados, lo cual ha incrementado el miedo y la incertidumbre. Por lo tanto, los factores nombrados se relacionan y crean un estado psicológico y emocional que puede afectar al desempeño académico. La familia es tomada como un apoyo emocional en cada etapa que pasa el ser humano en su vida, esencialmente en la académica. Pues hace posible que el individuo se centre en sus metas y objetivos educativos (Heredia y Camacho, 2014).

\section{Contexto socioeconómico}

El impacto del Covid-19 ha influenciado en la parte económica de todas las familias, limitando en la parte educativa y también relacionándose con la parte del trabajo que muchas personas han perdido, afectando a la economía de las familias (Pérez, 2020). Desde el año 1995 el Banco Mundial ha señalado que en un $40 \%$ a $50 \%$ los resultados académicos están fuertemente vinculados al impacto de las características socioeconómicas y familiares. Ahora, por el confinamiento la economía se ha debilitado en el país y los recursos económicos para pagar a los docentes de los cursos o materias se han aplazado, para los maestrantes que son profesionales también ha sido difícil la obtención de los recursos económicos (Ham, 2020), considerando aún más el pago de las mensualidades o según la modalidad de cancelación de la maestría el cual se encuentran cursando.

\section{CONCLUSIÓN}

En la actualidad se está utilizando una potente herramienta a nivel mundial como es la educación virtual para todos los niveles de educación, que se caracteriza por romper límites entre naciones y coartar los sueños de los estudiantes de viajar a un país determinado para desarrollar una carrera. La educación virtual abre las puertas en los países en donde se niega la posibilidad que estudien los niños y jóvenes por falta de espacios físicos como siempre ha sido un lamento para la población.

Las herramientas tecnológicas ejercen una presión de crecimiento en el conocimiento de 
la tecnología para poder realizar una mejor investigación en los diversos temas que se desconoce por falta de bibliotecas en contextos de educación.

Tanto docentes como estudiantes deben perder el miedo a la educación virtual y comprometerse con el aprendizaje de las herramientas tecnológicas, para alcanzar la calidad de la educación en esta modalidad, pues se ha comprobado en países desarrollados que esta nueva forma de llevar la educación, ha permitido llegar con mayor facilidad y eficiencia a todos los rincones de sus poblaciones y sin generar complicaciones con gran ahorro económico para las familias.

Los centros de educación superior como es la PUCE - Ambato de alto rendimiento están modificando la forma de acompañar al estudiante para que no sienta la soledad en momentos de dificultad, como ahora se está vivenciando el tiempo de pandemia, para ello se están diseñando tutorías con profesionales según las materias correspondientes $y$, también con personal especializado en problemas sociales, con el fin de realizar un seguimiento al docente que se está formando en sus aulas, cumpliendo la meta anhelada como es el de obtener un título de cuarto nivel.

\section{REFERENCIAS}

Aguirre R., D., Zhindón P., L., y Pomaquero Yuquilema, J. (2020). COVID-19 y la educación virtual Ecuatoriana. Investigación Académica., $5 . \quad$ Obtenido de http://investigacionacademica.com/index.p $\mathrm{hp} /$ revista/article/view/24

Alcántara Santuario, A. (2020). Educación y pandemia; una visión académica. México: UNAM

Basto, R. (18 de Mayo de 2017). La función docente y el rendimiento académico: una aportación al estado de conocimiento. Obtenido https://www.comie.org.mx/congreso/mem oriaelectronica/v14/doc/2030.pdf

Briceño Toledo, M., Correa Castillo, S., Valdés Montecinos, M., y Hadweh Briceño, M. (2020). Modelo de gestión educativa para programas en modalidad virtual de aprendizaje. Revista de Ciencias Sociales, 10. Obtenido de https://dialnet.unirioja.es/servlet/articulo? codigo $=7500759$

Calvo, F., Tamayo, R., Araujo, Á., Henríquez, L., y Morales, Y. (2019). Creación de una comunidad virtual de aprendizaje para la maestría pedagogía profesional de la Universidad Holguín. Revista Didasc@lia, 203-214. Obtenido de https://dialnet.unirioja.es/servlet/articulo? codigo $=7244458$

Campillo Labrandero, M., Martínez González, A., García Mijares, M., Guerrero Mora, L., y Sánchez Mendiola, M. (2019). Desempeño académico y egreso en 25 generaciones de estudiantes de la facultad de medicina de la UNAN. Educación Médica, 12. Obtenido de https://www.sciencedirect.com/science/ar ticle/pii/S1575181319301044

Castellanos, V., Latorre, D., Mateus, S., y Navarro, C. (2017). Modelo Explicativo del Desempeño Académico desde la Autoeficacia y los Problemas de Conducta. Revista Colombiana de Psicología, 149-161. doi:10.15446/rcp.v26n1.56221

Cervantes Arreola, D. I., Valadez Sierra, M. D., Valdéz Cuervo, A. A., y Tánori Quintana, J. (2018). Diferencias en autoeficacia académica, bienestar psicológico y motivación al logro en estudiantes universitarios con alto y bajo desempeño académico. Psicología desde el caribe, 7. Obtenido http://www.scielo.org.co/scielo.php?pid=S 0123417X2018000100007yscript=sci_abstractyt lng=en 
CGLU. (15 de Abril de 2020). Tecnologías digitales y la pandemia de COVID-19. Obtenido de https://www.uclg.org/sites/default/files/e ng_briefing_technology_es.pdf

Chong González, E. G. (2017). Factores que inciden en el rendimiento académico de los estudiantes de la Universidad Politécnica del Valle de Toluca. Latinoamericana de estudios., $6 . \quad$ Obtenido de https://www.redalyc.org/pdf/270/270504 22005.pdf

Contreras Álvarez, F. (2018). La Gamificación como estrategia de aprendizaje para mejorar el desempeño académico en estudiantes de tecnología. Educarnos, 35. Obtenido de https://revistaeducarnos.com/wpcontent/uploads/2018/09/educarnos31.pd f\#page $=27$

Edel, R. (2013). El rendimiento académico: concepto, investigación y desarrollo. REICE. Revista Iberoamericana sobre Calidad, Eficacia y Cambio en Educación, 1-16. Obtenido de http://www.redalyc.org/articulo.oa?id=551 10208

Estrada Molina, O., y Fuentes Cancell, D. (2021). Resultados de la capacitación semipresencial a profesores y tutores de la práctica profesional. Revista cubana de educación superior, 1 - 12. Obtenido de http://scielo.sld.cu/scielo.php?pid=S025743142021000100011yscript=sci_arttextytl ng=en

García Aretio, L. (2021). Algunas tipologías de educación. Researchgate UNED, 1-6.

García Peñalvo, F. (2021). Evaluación de competencias en entornos virtuales. Grupo de investigación e interacción y e-learning, $4 . \quad$ Obtenido de https://repositorio.grial.eu/handle/grial/2 196

García, L. (2017). Educación a distancia y virtual: calidad, disrupción, aprendizaje adaptativo y móvil. RIED. Revista Iberoamericana de Educación a Distancia, 925. doi:http://dx.doi.org/10.5944/ried.20.2.18 737

García, L. (05 de Junio de 2020). Coronavirus. Educación y uso de tecnologías en días de pandemia. Obtenido de http://ciencia.unam.mx/leer/1006/educaci on-y-uso-de-tecnologias-en-dias-depandemia

González, N., Tejeda, A., Espinosa, C., y Ontiveros, Z. (10 de Junio de 2020). Impacto psicológico en estudiantes universitarios mexicanos por confinamiento durante la pandemia por Covid-19. Obtenido de https://preprints.scielo.org/index.php/sciel o/preprint/download/756/1024/1068

Guerra, G. J. (2018). Educación en línea. Educación, 204.

Guzmán de la Cruz, L., y Ortiz Díaz, C. (2019). La evaluación auténtica como una alternativa para mejorar el rendimiento académico. Repositorio.Cuc.ed.co, 45. Obtenido de http://repositorio.cuc.edu.co/handle/1132 3/4905

Ham, A. (17 de Marzo de 2020). El impacto económico y social de la pandemia COVID19 y recomendaciones de política para Honduras. Obtenido de https://www.undp.org/content/dam/rblac /Policy\%20Papers\%20COVID\%2019/UND P-RBLAC-CD19-PDS-Number4-ESHonduras.pdf

Heredia, Y., y Camacho, D. (2014). Factores que afectan el desempeño académico. México: Yolanda Heredia y Dulce Camacho. Obtenido de https://www.researchgate.net/publication /281294042_Factores_que_afectan_el_dese mpeno_academico

Hernández, J., Tobón, S., González, L., y Guzmán, C. (2015). Evaluación socio-formativa y rendimiento académico en el programa de posgrado en línea. Paradigma., 33. Obtenido de

http://ve.scielo.org/scielo.php?script=sci_ar ttextypid=S1011-22512015000100003 
Isaza, L., y Henao, G. (2012). Actitudes-Estilos de enseñanza: Su relación con el rendimiento académico. International Journal of Psychological Research, 133-141. Obtenido de

http://www.redalyc.org/articulo.oa?id=299 023539015

Izar, J., Ynzunza, C., y López, H. (2011). Factores que afectan el desempeño académico de los estudiantes de nivel superior en Rioverde, San Luis Potosí, México. Revista de Investigación Educativa, 1-18. Obtenido de https://cdigital.uv.mx/bitstream/handle/1 23456789/10399/Izar-

desempeno $\% 20$ academico.pdf?sequence $=$ 2yisAllowed=y

Jaramillo, D. (2015). Sobre didáctica y clase virtual. Revista Virtual Universidad Católica del Norte, 1-8. Obtenido de https://www.redalyc.org/pdf/1942/1942 20381003.pdf

López Angulo, Y., Pérez Villalobos, M., y Díaz, A. (2020). Apoyo social, sexo y área del conocimiento en el rendimiento académico. Formación Universitaria, 16. Obtenido de https://scielo.conicyt.cl/scielo.php?pid=S0 718-

50062020000300011yscript=sci_arttextytl $\mathrm{ng}=\mathrm{p}$

López, M., y Estrada, A. (20 de Septiembre de 2010). Desempeño académico de estudiantes en educación virtual. Algunos factores negativos. Obtenido de https://www3.azc.uam.mx/sieee/cuartose minario/ponencias/ponencia10.pdf

Marciniak, R. (2017). Propuesta metodológica para el diseño del proyecto de curso virtual: aplicación piloto. Revista Apertura, 74-95.

Doi: http://dx.doi.org/10.32870/Ap.v9n2.991

Martínez, R., y Heredia, Y. (2010). Tecnología Educativa en el salón de clase: Estudio retrospectivo de su impacto en el desempeño académico de estudiantes universitarios del área de Informática. Revista Mexicana de Investigación Educativa, 1-6. Obtenido de
http://www.iiis.org/CDs2009/CD2009CSC /SIECI2009/PapersPdf/X387HO.pdf

Medina, A., y Salvador, F. (2009). Didáctica General. Madrid: PEARSON EDUCACIÓN. Obtenido de http://ceummorelos.edu.mx/libros/didacticageneral.p df

Mejía Serrano, J., Silva Giraldo, C., y Rueda Mahecha, Y. (2020). Ruta de atención psicosocial para docentes con síndrome de burnout a causa de la cuarentena. Revista de investigación en gestión industrial, seguridad y salud en el trabajo., 1-10. Obtenido de http://editorialeidec.com/revista/index.ph $\mathrm{p} /$ GISST/article/view/86

Mesén Meneses, P. (2020). Un aprendizaje significativo e innovador por medio de habilidades y competencias en la óptica de la educación virtual. Revista el labrador, 3$15 . \quad$ Obtenido de https://www.uisil.ac.cr/uisiljournal/index.php/Revista/article/view/1 43

Ministerio de Educación. (2017). REGLAMENTO GENERAL A LA LEY ORGÁNICA DE EDUCACIÓN INTERCULTURAL. Obtenido de REGLAMENTO GENERAL A LA LEY ORGÁNICA DE EDUCACIÓN INTERCULTURAL:

https://educacion.gob.ec/wpcontent/uploads/downloads/2017/05/Re glamento-General-Ley-Organica-

Educacion-Intercultural.pdf

Mogro C, S. (2020). Tendencias tecnológicas de la educación a distancia. Educallajta, 1 - 11. Obtenido de https://www.researchgate.net/profile/Sau l_Mogro3/publication/342065308_TENDE NCIAS_TECNOLOGICAS_DE_LA_EDUCACIO N_A_DISTANCIA/links/5f88519b92851c14 bcc92f6c/TENDENCIAS-TECNOLOGICASDE-LA-EDUCACION-A-DISTANCIA.pdf

Mondragón Albarrán, C., Cardoso Jiménez, D., y Bobadilla Beltrán, S. (2017). Hábitos de estudio y rendimiento académico. Revista Iberoamericana para la investigación y el desarrollo educativo., 7. Obtenido de 
http://www.scielo.org.mx/scielo.php?pid= S2007-

74672017000200661yscript=sci_arttext

Núñez Morales, V. (2020). Impacto de la educación virtual en el deporte en la república de Colombia. Edu-Física, 131. Obtenido de http://revistas.ut.edu.co/index.php/edufis ica/article/view/2085

Ordorika, I. (2020). Pandemia y educación superior. Revista de la educación superior, 7. Obtenido de http://www.scielo.org.mx/scielo.php?scrip $\mathrm{t}=$ sci_arttextypid=S018527602020000200001

Oropeza-Amador, M., Hernández - Aguirre, F., y Reyes - García, M. (2021). Narrar la memoria en tiempos de pandemia: el no lugar del otro en el terreno educativo. CoPala, 1-18. Obtenido de http://revistacopala.net/index.php/ojs/art icle/view/73

Ortiz, W., Santos, L., y Rodríguez, E. (2020). Estrategias didácticas en entornos virtuales de enseñanza-aprendizaje universitarios. Revista Electrónica Opuntia Brava, 68-83. Obtenido de http://opuntiabrava.ult.edu.cu/index.php/ opuntiabrava/article/view/1105/1345

Palacios, J., y Andrade, P. (2017). Desempeño académico y conductas de riesgo en adolescentes. Revista de Educación y Desarrollo, 1-12. Obtenido de http://www.cucs.udg.mx/revistas/edu_de sarrollo/anteriores/7/007_Palacios.pdf

Pando, V. (2018). Tendencias didácticas de la educación virtual: Un enfoque interpretativo. Scielo, 463-505. doi:http://dx.doi.org/10.20511/pyr2018.v 6n1.167

Pardo Cueva, M., Chamba Rueda, L., Higuerey Gómez, Á., y Jaramillo Campoverde, B. (2020). Las TIC y rendimiento académico en la educación superior: una relación potenciada por el uso del Padlet. risti, 7. Obtenido de https://www.researchgate.net/profile/Ma riuxi_Pardo-

Cueva/publication/348237110_Las_TIC_y_ rendimiento_academico_en_la_educacion_s uperior_Una_relacion_potenciada_por_el_u so_del_Padlet/links/5ff4a97b45851553a0 226d83/Las-TIC-y-rendimiento-

academico-en-la-educ

Parra Acosta, H., Tobón, S., y López Loya, J. (2015). Docencia socio-formativa $y$ desempeño académico en la educación superior. Paradigma, 36.

Pérez, I. (04 de Abril de 2020). Coronavirus. Impactos económicos de la pandemia. Obtenido de http://ciencia.unam.mx/leer/976/coronav irus-impactos-economicos-de-la-pandemia

Pérez, M., y Urquijo, S. (2010). Depresión en adolescentes. Relaciones con el desempeño académico. Psicología Escolar e Educacional, 49-58. Obtenido de https://www.scielo.br/pdf/pee/v5n1/v5n 1a06.pdf

Pérez, s. (Enero de 2016). "MATERIAL DIDÁCTICO PARA LA INICIACIÓN A LA LECTURA". Obtenido de http://recursosbiblio.url.edu.gt/tesiseortiz /2016/05/84/Perez-Skarltt.pdf

Quintero, M. T., y Orozco, G. (2013). El desempeño académico: una opción para la cualificación de las instituciones educativas. Plumilla Educativa, 93-115. Obtenido de https://dialnet.unirioja.es/descarga/articu lo/4756664.pdf

Robinet, A., y Pérez, M. (2020). Estrés en los docentes en tiempos de pandemia Covid19. Polo del Conocimiento, 637-653. doi:10.23857/pc.v5i12.2111

Rojas, N., Pérez, F., Torres, I., y Peláez, E. (2014). Las aulas virtuales: una opción para el desarrollo de la Educación Médica. EDUMECENTRO, 231-247. Obtenido de http://scielo.sld.cu/pdf/edu/v6n2/edu162 14.pdf

Ruz Fuenzalida, C. (2021). Educación virtual y enseñanza remota de emergencia en el contexto de educación superior. Revista Saberes educativos, 12. Obtenido de https://revistateoriadelarte.uchile.cl/index .php/RSED/article/view/60713 
Salgado, E. (16 de Febrero de 2015). La enseñanza y el aprendizaje en modalidad virtual desde la experiencia de estudiantes y profesores de posgrado. Obtenido de https://www.researchgate.net/publication /272821004_La_ensenanza_y_el_aprendiza je_en_modalidad_virtual_desde_la_experien cia_de_estudiantes_y_profesores_de_posgra do

Sanabria Cárdenas, I. (2020). Educación virtual: oportunidad para aprender a aprender. Análisis Carolina, 3 - 10.

Saza, I. (2016). Estrategias didácticas en tecnologías web para ambientes virtuales de aprendizaje. Revista Praxis, 103-110. doi:http://dx.doi.org/10.21676/23897856 .1851

Suárez, C. (20 de Octubre de 2010). Estructura didáctica virtual para Moodle. Obtenido de https://www.raco.cat/index.php/DIM/arti cle/download/138930/189974/

Suárez, S., Elías, R., y Zarza, D. (2016). Factores Asociados al Rendimiento Académico de Estudiantes de Paraguay: Un Análisis de los Resultados del TERCE. REICE. Revista Iberoamericana sobre Calidad, Eficacia y
Cambio en Educación, 113-133. doi:https://doi.org/10.15366/reice2016.1 4.4.006

Torres Santos, E. (2020). Identificación de condiciones laborales en el personal docente de una universidad con metodología de educación virtual y a distancia, a partir de la aplicación del modelo POTAM. ProQuest, 1-6. Obtenido de

https://search.proquest.com/openview/3 4c99a7a7210bd85e1add3e7d8c079dc/1? pq-origsite $=$ gscholarycbl $=1216408$

Urquijo, S. (2010). Auto-concepto y desempeño académico en adolescentes. Relaciones con sexo, edad e institución. Psico-USF, 211$218 . \quad$ Obtenido de https://www.scielo.br/pdf/pusf/v7n2/v7 n2a10.pdf

Xu, Y., y García González, M. (2021). Análisis histórico de la vinculación entre educación superior y el desarrollo económico en China. Revista cubana de educación superior., 3- $20 . \quad$ Obtenido de http://scielo.sld.cu/scielo.php?script=sci_a rttextypid=S0257-43142021000100007 